\title{
Use of solar energy for biodiesel production and use of biodiesel waste as a green reaction solvent
}

\author{
Brian M Agee ${ }^{1}$, Gene Mullins ${ }^{2}$ and Daniel J Swartling ${ }^{2^{*}}$
}

\begin{abstract}
Due to the depletion of fossil fuel energy sources, new alternative energy sources are becoming prevalent in our society. Biodiesel has been recognized as an attractive replacement for depleting energy sources since it is produced mainly from vegetable oils and animal fats, is a renewable resource, and is non-toxic. The synthesis of biodiesel involves heating a triglyceride with methanol (or ethanol) under strongly basic conditions. Since fossil fuels are used for electrical energy in the United States, the amount of electricity required to heat this reaction requires the use of non-renewable resources. An effective means for minimizing the amount of electricity needed to drive chemical reactions to completion is proposed through the use of solar parabolic reflectors. In this study, a technique was developed to incorporate recently proposed solar reflectors developed from satellite dishes into the synthetic procedure for biodiesel. Through the use of our technique, the generation of carbon dioxide waste during biodiesel production has been eliminated. Another area of environmental concern in biodiesel production is the generation of waste by-products (glycerol). A technique has been developed that incorporates the use of recovered biodiesel waste glycerol as the solvent system for Wolff-Kishner reduction reactions. The reduction of isobutyryl chloride has been performed successfully using biodiesel waste glycerol as the solvent system and solar irradiation as the heat source for the chemical reaction.
\end{abstract}

Keywords: Solar organic synthesis, Solar reflector, Biodiesel synthesis, Biofuel synthesis, Wolff-Kishner reduction, Green chemistry, Solar energy, Reactions and methods

\section{Background}

Approximately 300 million years ago, plants and animals that were living in the ocean absorbed and stored energy from the sun in their bodies as carbon. Once these animals died, their bodies sank to the ocean floor, where they were covered with layers of sediment deposits, which were heated and compacted until they became oil [1]. Furthermore, the release of carbon dioxide through the burning of fossil fuels has greatly contributed to the period of global warming that Earth is currently undergoing [2]. To give an estimate of the amount of carbon dioxide that is released through the burning of fossil fuels, it has been reported that for every gallon of gasoline that a car burns, 9.98 kilograms of carbon dioxide gas is released into the atmosphere [3].

\footnotetext{
* Correspondence: dswart@tntech.edu

${ }^{2}$ Department of Chemistry, Tennessee Technological University, Cookeville, TN 38505, USA

Full list of author information is available at the end of the article
}

A solution to the problem of fossil fuel depletion is the realization that people need to rely on new fuel sources that are developed from replenishable sources. An example of a renewable fuel source would be vegetable oil. When vegetable oil is used as a fuel source, crops that are used to produce the vegetable oil can be regenerated in an endless cycle as long as people take care of the land in which the crops are growing. Therefore, since the raw material that the fuel is being produced from is replenishable, vegetable oil can be viewed as a renewable fuel source whose supply will potentially never run out.

Biodiesel is the methyl (or ethyl) ester of vegetable oil and is a clean burning, diesel fuel replacement that is an exact substitute for existing compression engines [4]. It can be used in diesel engines as a pure fuel or as a blended mixture with petroleum (in any percentage). Aside from being produced from a renewable feedstock, biodiesel also has other benefits such as a reduction of 
carbon dioxide emissions by up to $80 \%$ in comparison to petroleum based diesel (Table 1) [5].

The oil needed to synthesize biodiesel can come from various sources. Currently, there are over 350 different species of oil-producing plants with the top oil-producing plants averaging between $5,000 \mathrm{~kg}$ oil/hectare to $145 \mathrm{~kg}$ oil/hectare (Table 2) [6]. Some of these plants have the capability to be harvested more than once per year, increasing their net oil output. Furthermore, the oil does not have to be pure, unused oil. A study published by Nye et al. was one of the first studies that was capable of demonstrating that used frying oil can be converted to diesel fuel with purity as good as unused oil samples [7].

Chemically, biodiesel is the alkyl esters that are synthesized from a transesterification reaction on plant oils. This reaction typically consists of a two-step, base catalyzed reaction of the plant oil with an alcohol. In order to prepare biodiesel, most procedures recommend that the vegetable oil, alcohol, and base are vigorously mixed together (through the use of magnetic or mechanical stirring) while being heated to alcohol reflux temperatures [8].

However, using the outlined procedure, there are several areas in which the chemical procedure needs improvement to alleviate waste generation and reduce hazard levels. Electricity is one area that needs improving since it is needed for the synthetic procedure as it has currently been outlined. In the United States, the majority of electricity used is generated from fossil fuels [9]. Furthermore, there are approximately 1.3 billion people globally that live without electricity that would not be able to synthetically produce biodiesel as currently outlined [10]. Therefore, in order to make the synthetic production of biodiesel more sustainable, alternative heating sources must be investigated.

The alcohols used in the transesterification reaction to produce biodiesel typically include the use of methanol or ethanol. Methanol is a sustainable reactant, as it comes from the destructive distillation of wood; however, there are several human health hazards affecting the central nervous system that make methanol less favorable of a reactant. For instance, if methanol is ingested, a $10 \mathrm{~mL}$ sample can cause the person to become permanently blind, while a $30 \mathrm{~mL}$ sample can be potentially fatal [11]. Ethanol is likewise a sustainable reactant source, as it is produced as

Table 1 Comparison of $\mathrm{CO}_{2}$ emission in 2004 VW Jetta Wagon using various engines/fuels

\begin{tabular}{lll}
\hline Fuel type & City/Highway MPG & $\mathbf{C O}_{\mathbf{2}}$ Emissions (kg/year) \\
\hline 2 L Gasoline & $23 / 30$ & 7400 \\
1.9 L PetroDiesel & $32 / 43$ & 5800 \\
$1.9 \mathrm{~L}$ & $32 / 43$ & 4900 \\
$20 \%$ BioDiesel & & \\
1.9 L 100\% BioDiesel & $32 / 43$ & 1300 \\
\hline
\end{tabular}

Table 2 Oil production averages for ten highest oil-producing crops

\begin{tabular}{lll}
\hline Plant & Latin name & kg oil/hectare \\
\hline Oil palm & Elaeis guineensis & 5000 \\
Coconut & Cocos nucifera & 2260 \\
Jatropha & Jatropha curcas & 1590 \\
Rapeseed & Brassica napus & 1000 \\
Peanut & Arachis hypogaea & 890 \\
Sunflower & Helianthus annuus & 800 \\
Safflower & Carthamus tinctorius & 655 \\
Soybean & Glycine max & 375 \\
Hemp & Cannabis sativa & 305 \\
Corn & Zea mays & 145 \\
\hline
\end{tabular}

a byproduct of the metabolic processing of yeast [12]. However, unlike methanol, ethanol is much less poisonous to the central nervous system and is safe for human consumption in moderation at diluted concentrations [13]. Therefore, if possible, the use of ethanol as the alcohol reactant would enhance the safety of the synthetic process of biodiesel.

Glycerol is produced as a by-product in the synthesis of biodiesel. For every 3.8 liters of biodiesel produced, 476 grams of glycerol is produced [14]. Pure glycerol is used to make hundreds of products ranging from solvents and preservatives in the food industry to pharmaceutical/personal care products [6].

However, this crude glycerol contains any unreacted alcohol, unreacted base, and trace amounts of water and salts. In order to refine this crude glycerol into a product that is useable according to industry standards, several high energy requirement purification techniques must be employed. For example in order to remove the unused alcohol and water, the crude glycerol must be heated to boiling. Furthermore, a high pressure/temperature distillation process is often required for industrial processing of the crude glycerol [15].

In order to make this refinement process more sustainable, attempts must be made to reduce the amount of energy required to purify the recovered glycerol from the production of biodiesel. Attempts must also be made to develop chemical reaction techniques that could use the refined glycerol.

The goal of this study is to synthesize biodiesel without the use of any fossil fuels for electricity. A solar reflector heat source was developed and used to examine its ability to synthesize biodiesel. This particular reaction was chosen based on its current use in synthesis processes used in industry, and because advancements in the reaction are currently needed in order to incorporate more sustainable techniques. For instance, the Amereco Biofuels Corporation has pursued technologies to commercialize 
the creation, processing and delivery of renewable biofuel products and uses a similar technique in the synthesis of biodiesel for their corporation [16].

To make the synthetic process greener, the electric heat source is exchanged for reflected solar irradiation. Also, methanol and ethanol have been used as the alcohol for the reaction in order to determine if there are any differences between the use of either alcohol. The recovered glycerol is purified using only solar irradiation as a heating source (no fossil fuels or electricity are used to purify the glycerol). Once recovered, the glycerol is used as the solvent for Wolff-Kishner reduction reaction, which is also heated to reflux using only solar irradiation. Also, as a result of this work, a method of preparing biodiesel in a manner that is $100 \%$ electricity free and generates very little waste will be demonstrated.

\section{Results and discussion}

A solar reflector was designed through the repurposing of unused satellite dishes into a reflective parabolic mirror that will serve as the sole heat source to drive synthetic chemical reactions to completion [17]. To transform the satellite dishes into solar reflectors, the surface of the dish was completely covered with Metalized Mylar tape to attain the reflective properties needed to generate heat. It was discovered that the feed horn of the satellite dish is located at the focal point. Therefore, the feed horn of the dish was removed and reaction flasks were placed in this position in order to achieve maximum intensity from the directed sunlight.

In order to test the scalability of this procedure using the solar reflector as the sole heat source, the reaction was performed at various scales. The first scale of the reaction that was used was a milimolar scale that could be used for educational purposes. The second reaction used was scaled up to be ten times the volume of the first scale. The third reaction used was scaled to be 40 times the volume of the first scale (now on the mole scale).

Upon obtaining data from the synthesis of biodiesel using only solar irradiation as the heat source, it was concluded that the solar heat source provided a reliable, efficient alternative heating source that produced very high product yields. Additionally, the biodiesel product yields were similar to the yields that were obtained in an in-lab study using the same molar rations (Table 3). The statistically equal results for the solar and in-lab synthesis suggests that the heat exchange process that is required for this synthetic procedure is equivalent between both heating techniques. Furthermore, the large scale biodiesel reaction $(4000 \mathrm{~mL}$ round bottom flask) demonstrated that this method of performing synthetic chemical reactions is capable of being scaled to much larger capacity reactions.
Table 3 Comparison of percent yields for the biodiesel in Solar vs. In-Lab study using same molar concentrations

\begin{tabular}{lll}
\hline Alcohol & Scale (amount of vegetable oil) & Percent yield \\
\hline Methanol & $60 \mathrm{~mL}$ & $95.5 \%$ \\
& $600 \mathrm{~mL}$ & $91.4 \%$ \\
\multirow{2}{*}{ Ethanol } & $60 \mathrm{~mL}$ & $93.0 \%$ \\
& $600 \mathrm{~mL}$ & $94.4 \%$ \\
\hline
\end{tabular}

This work demonstrates that the solar heat source that has been developed can be used successfully during any time of the year for the production of biodiesel. However, there are several factors that affect its efficiency. As long as there is enough sun present to produce at least approximately $400 \mathrm{~W} / \mathrm{m}^{2}$ of solar irradiation, efficient heating can be obtained in a reasonable amount of time (Table 4). On days that are mostly cloudy, there typically is not enough solar irradiation to produce enough energy to heat a chemical reaction. Occasionally, passing clouds will provide loses in heat. However, it was discovered that upon increasing the volume of the reaction to the medium and large scale, the larger mass was capable of retaining heat for a longer period of time and the effect of passing clouds was not a great on the large scale reactions. Additionally, it was discovered that if the time that it took the cloud to pass over the sun was less than ten minutes, the solution continued to boil, even without the full exposure to the directed solar irradiation.

Seasonal trends and outside ambient temperature also seem to play little to no role in the technique that has been developed (Table 4). Using the small scale methanol biodiesel synthetic procedure as a template, we were capable of attaining statistically equivalent biodiesel yields during each of the four seasonal periods. Moreover, outside ambient temperature seemed to have no effect on heating the reaction to reflux temperatures. The colder temperatures in the spring/winter months provided the added benefit of keeping the condenser cooler than in the fall/summer months. By keeping the condenser cooler, more of the excess methanol was able to be recovered, rather than have a portion of it be lost out of the condenser.

It should be noted that no electricity at all was used in the synthesis or purification of the biodiesel or glycerol. All heat supplied to synthesize biodiesel and distill methanol/ethanol away from the recovered glycerol was generated through sunlight. Furthermore, it was successfully demonstrated that high speed stirring via a magnetic stir bar is not needed in this synthetic process. It was observed that sufficient mixing is capable of being achieved through reflux solvent mixing, accompanied with occasional, slight rocking of the reflector dish to aide in the mixing process.

It appears that the use of ethanol over methanol also has no effect on the amount of biodiesel produced. Similar biodiesel yields were obtained in each scaled reaction 
Table 4 Seasonal variations

\begin{tabular}{lllll}
\hline & Spring (5/15/14) & Summer (6/6/14) & Fall (11/18/12) & Winter (1/30/14) \\
\hline Time to begin reflux (minutes) & 10 & 2 & 4 & 4 \\
Reflux temperature & $76^{\circ} \mathrm{C}$ & $74^{\circ} \mathrm{C}$ & $75^{\circ} \mathrm{C}$ & $75^{\circ} \mathrm{C}$ \\
Average outside temperature & $12^{\circ} \mathrm{C}$ & $25^{\circ} \mathrm{C}$ & $23^{\circ} \mathrm{C}$ & $1^{\circ} \mathrm{C}$ \\
Outside conditions & Mostly cloudy & Sunny & Partly cloudy & Partly cloudy \\
Average solar irradiation $\left(\mathbf{W} / \mathbf{m}^{2}\right)$ & 378 & 905 & 635 & 642 \\
Percent yield & $92 \%$ & $94 \%$ & $90 \%$ & $95 \%$ \\
\hline
\end{tabular}

that was conducted (Table 5). The only disadvantage of using ethanol over methanol was the observation that slight excess of alcohol and base must be used when ethanol is the reacting alcohol.

Through the use of a P4400 Kill A Watt ${ }^{\circ}$ power meter [18], the energy usage levels in kilowatt-hours (KWH) for the synthesis of biodiesel and the purification of the reaction by-product, glycerol was determined. It was determined that the synthesis of biodiesel requires to be heat to a temperature of approximately $75^{\circ} \mathrm{C}$ for a period of one hour. This reaction used $0.357 \mathrm{KWH}$. Furthermore, it was determined that $0.178 \mathrm{KWH}$ was used in the purification of the glycerol by-product. Thus, the total synthetic/purification procedure for a typical reaction to synthesize biodiesel and purify the glycerol byproduct requires $0.535 \mathrm{KWH}$ of energy.

Through the use of the greenhouse gas equivalencies calculator [19] provided by the United States Environmental Protection Agency, the $0.535 \mathrm{KWH}$ of energy required to perform this process generates $0.369 \mathrm{~kg}$ of carbon dioxide. Thus, through the use of our technique of using directed solar irradiation as the sole heat source, greenhouse gas emissions for this synthetic process and thereby decreasing the carbon footprint of this reaction are being eliminated.

Not only was biodiesel synthesized through the use of only solar irradiation, but a new synthetic use for the byproduct of the reaction was discovered. Incorporation of the by-product (glycerol) as the reaction solvent for Wolff-Kishner reduction reactions is a significant step in making Wolff-Kishner reductions more environmentally friendly. In a previous study, it was demonstrated that

Table 5 Comparison of biodiesel yields using various alcohols (Methanol vs. Ethanol)

\begin{tabular}{lll}
\hline & In-lab & Solar \\
\hline Small scale (methanol) & $93.8 \%$ & $95.5 \%$ \\
Small scale (ethanol) & $92.9 \%$ & $91.4 \%$ \\
Medium scale (methanol) & $94.7 \%$ & $93.0 \%$ \\
Medium scale (ethanol) & $91.5 \%$ & $94.4 \%$ \\
\hline
\end{tabular}

typical Wolff-Kishner solvent systems such as Ethylene Glycol and Diethylene Glycol (which are toxic) could be exchanged for the non-toxic Propylene Glycol [20]. By exchanging the solvent system of the reaction to waste glycerol that is generated through the production of biodiesel, this reaction has been performed under much more environmentally favorable, and more sustainable conditions. Using the same reaction conditions, product yields for the Wollf-Kisher reduction reaction of isobutyrophenone remains comparable no matter what solvent system is being used (Table 6).

Also, through the purification process of glycerol, any unused alcohol, which could be recycled and used in future work, was recovered. Furthermore, during the glycerol recovery process, we generate free fatty acids (FFA), which can be used to synthesize more biodiesel. Additionally, during this process, any unreacted sodium hydroxide is converted to sodium chloride, which can be recovered and reused. The FFA can undergo transesterification reactions to generate biodiesel just as vegetable oil. During the entire chemical procedure, the use of sodium sulfate to dry the biodiesel is the only step in which a waste product is generated that has no further purpose and is truly considered waste. Allowing the biodiesel to stand for a period of time (several days) provides a means to remove the majority of the water from the biodiesel sample without having to use the sodium sulfate drying agent. By allowing the biodiesel to stand, the water will eventually separate from the biodiesel and the solution will form two layers (water and biodiesel). Thus, the water can be removed and a fairly dry sample of biodiesel can be obtained without the use of a drying agent.

Table 6 Comparison of percent yields for the Wolff-Kishner reduction of isobutyrophenone using various solvents systems

\begin{tabular}{ll}
\hline Solvent & Percent yield \\
\hline Ethylene glycol & $68.5 \%$ \\
Diethylene glycol & $75.1 \%$ \\
Propylene glycol & $73.5 \%$ \\
Glycerol (from biodiesel synthesis) & $70.0 \%$ \\
\hline
\end{tabular}




\section{Experimental}

All procedures were run in triplicate to obtain the reported results.

\section{Biodiesel synthesis general procedure}

For reactions in which methanol was the alcohol used, sodium methoxide was generated in a round bottom flask by dissolving sodium hydroxide in methanol. For reactions in which ethanol was the alcohol used, sodium ethoxide was generated in a round bottom flask by dissolving sodium hydroxide in ethanol. It should be noted that excess alcohol was added in case any of the alcohol escaped during the reaction process. The sodium methoxide (or sodium ethoxide) was mixed with soybean oil in a $24 / 40$ round bottom flask that had been painted black using VHT ${ }^{\circ}$ Flame Proof paint. The round bottom flasks were $100 \mathrm{~mL}$ (small scale), $1000 \mathrm{~mL}$ (medium scale), and $4000 \mathrm{~mL}$ (large scale). No stir-bar is placed into the flask since the refluxing liquid was sufficient to thoroughly mix the solutions. The flask was attached to the solar reflector in the position that the feed horn of the satellite dish was located to provide the best location for the directed focal point of sunlight (Figures 1, 2, and 3). A modified Baum et al. Allign-type condenser, filled with propylene glycol and capped with pipet bulbs to insure that the propylene glycol stayed in the condenser, was attached to the round bottom flask [21]. The solar heat source was then moved into a position in which it was reflecting sunlight onto the bottom of the round bottom flask. The solution was allowed to heat at reflux temperature $\left(70^{\circ} \mathrm{C}\right.$ for methanol; $83^{\circ} \mathrm{C}$ for ethanol) for one hour. After the one hour of reflux, the solution was moved out of the focal point and the solution was

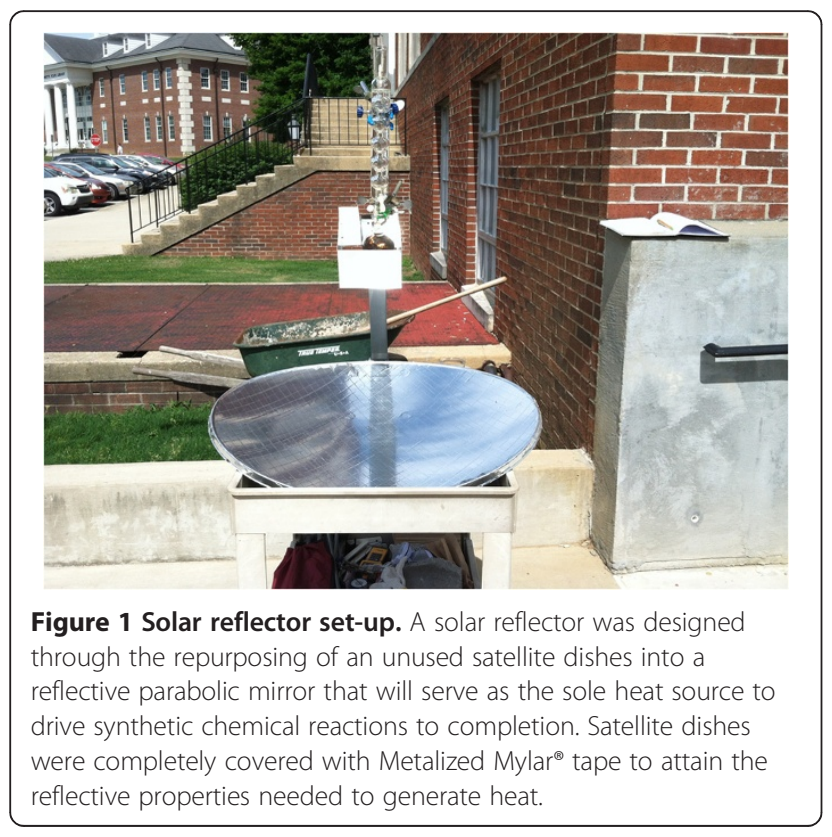

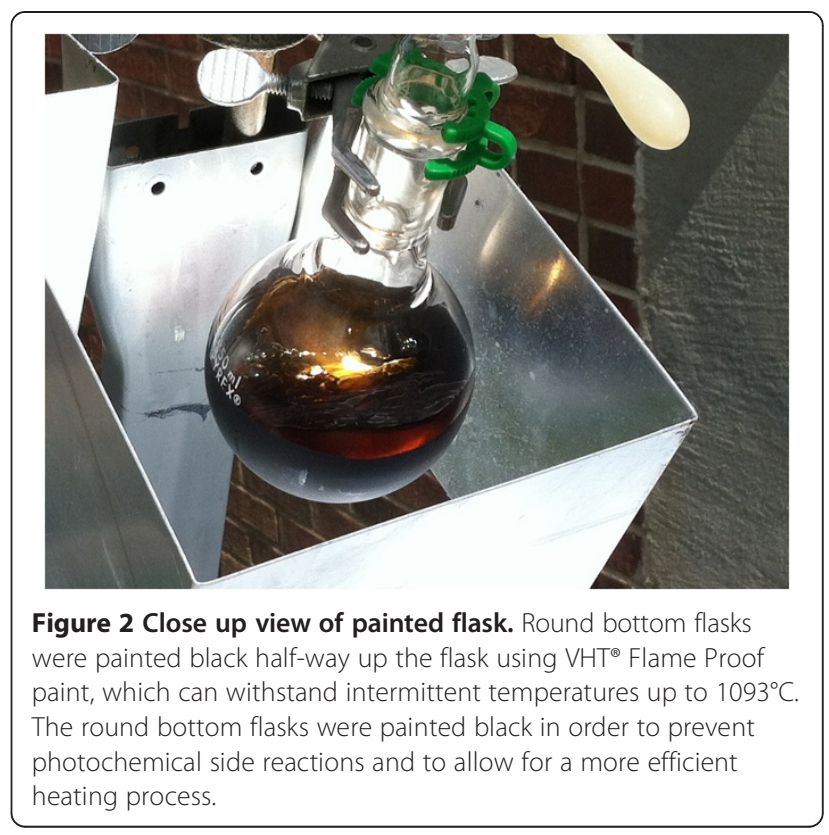

allowed to cool to ambient temperature. During this time, two notable layers formed. The top layer was determined to be biodiesel, while the bottom layer was crude glycerol. The solutions were isolated using a separatory funnel. The biodiesel layer was dried using

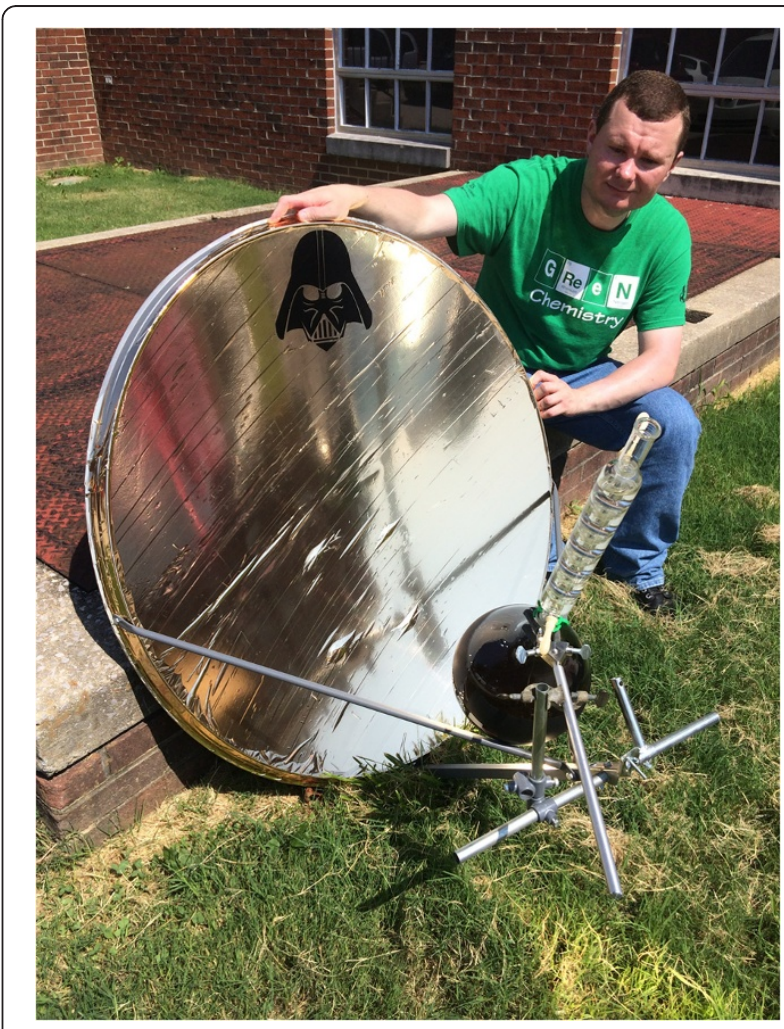

Figure 3 D.E.A.T.H dish set-up. Larger size dish to provide more surface area to expand procedure to larger scaled reactions. 
sodium sulfate, while the crude glycerol underwent a purification process.

\section{Biodiesel synthesis (small scale - using methanol)}

A solution of sodium methoxide was prepared by dissolving crushed sodium hydroxide pellets $(13.2 \mathrm{mmol}$, $0.527 \mathrm{~g})$ in $99.8 \%$ methanol $(25.0 \mathrm{~mL})$. The sodium hydroxide was dissolved in the methanol through gently swirling the mixture in an Erlenmeyer flask for 180-300 seconds. Soybean oil (54.3 g, $60.0 \mathrm{~mL}$ ) was combined with the freshly prepared sodium methoxide solution in a painted $250 \mathrm{~mL}$ round bottom flask and heat to reflux $\left(70^{\circ} \mathrm{C}\right)$ for one hour using solar irradiation as the heat source. Biodiesel product (52.200 g, 95.5\%) was collected and dried using anhydrous sodium sulfate $(0.513 \mathrm{~g}) .{ }^{13} \mathrm{C}$ NMR (ppm) $\left(\mathrm{CDCl}_{3}\right): 174.1,130.0,129.9,127.9,51.2$, $33.9,31.8,29.6,29.5,29.5,29.3,29.1,29.0,29.0,27.1$, 25.5, 24.8, 22.6, 22.5, 14.0, 13.9. GC: $16.184 \mathrm{~min}$. MS (m/z): 55.0, 69.0, 73.9 (base peak), 86.9, 142.9, 170.9, 184.9, $198.9,227.0,241.1,270.0\left(\mathrm{~m}^{+}\right.$peak - palmitic acid methyl ester). GC: $19.092 \mathrm{~min}$. MS (m/z): 55.0, 66.9 (base peak), 80.9, 95.0, 109.0, 120.9, 135.0, 149.0, 177.9, 262.0, $293.9\left(\mathrm{~m}^{+}\right.$peak -methyl linoleate). GC: $19.208 \mathrm{~min}$. MS $(\mathrm{m} / \mathrm{z})$ : 55.0, 66.9 (base peak), 80.9, 95.0, 109.0, 123.0, 135.0, 149.0, 164.8, 179.8, 206.9, 222.0, 264.0, $295.9\left(\mathrm{~m}^{+}\right.$ peak -methyl oleate). GC: $19.666 \mathrm{~min}$. MS: 55.0, 66.9, 73.9 (base peak), 86.9, 142.9, 199.0, 241.0, 255.1, 281.0, $298.0\left(\mathrm{~m}^{+}\right.$peak -methyl stearate).

\section{Biodiesel synthesis (small scale - using ethanol)}

A solution of sodium ethoxide was prepared by dissolving crushed sodium hydroxide pellets $(15.2 \mathrm{mmol}, 0.607 \mathrm{~g})$ in 200 proof - absolute, anhydrous ethanol (40.0 mL). The sodium hydroxide was dissolved in the ethanol through gently swirling the mixture in an Erlenmeyer flask for 420-600 seconds. Soybean oil (52.7 g, 59.7 mL) was combined with the freshly prepared sodium ethoxide solution in a painted $250 \mathrm{~mL}$ round bottom flask and heat to reflux $\left(83^{\circ} \mathrm{C}\right)$ for one hour using solar irradiation as the heat source. Biodiesel product (48.216 g, 91.4\%) was collected and dried using anhydrous sodium sulfate $(0.518 \mathrm{~g}) .{ }^{13} \mathrm{C}$ NMR (ppm) $\left(\mathrm{CDCl}_{3}\right): 173.8,129.8,127.9,127.8, \delta 60.0$, $\delta 34.2,31.4,29.6,29.6,29.5,29.2,29.1,29.0,27.1,25.5$, 24.8, 22.5, 14.1, 13.9. GC: $17.325 \mathrm{~min}$. MS (m/z): 55.0, 73.0, 87.9 (base peak), 100.8, 114.8, 128.8, 142.9, 156.9, 170.9, 185.0, 198.8, 213.1, 227.1, 241.1, 284.0 ( $^{+}$peak palmitic acid ethyl ester). GC: $20.198 \mathrm{~min}$. MS: 55.0, 66.9 (base peak), 80.9, 95.0, 109.0, 120.9, 135.0, 149.0, 163.9, 177.9, 262.1, $308.0\left(\mathrm{~m}^{+}\right.$peak - ethyl linoleate). GC: $20.316 \mathrm{~min}$. MS (m/z): 55.0 (base peak), 66.9, 80.9, 95.9, 123.0, 135.0, 151.0, 166.0, 180.0, 222.0, 246.1, 264.2, 310.1 $\left(\mathrm{m}^{+}\right.$peak -ethyl oleate). GC: $20.781 \mathrm{~min}$. MS (m/z): 55.0, 61.0, 73.0, 87.8 (base peak), 100.8, 114.8, 128.9, 142.9,
156.9, 171.0, 185.0, 199.0, 213.1, 227.1, 241.1, 255.1, 269.1, 283.0, $312.2\left(\mathrm{~m}^{+}\right.$peak - ethyl stearate).

\section{Biodiesel synthesis (medium scale - using methanol)}

A solution of sodium methoxide was prepared by dissolving crushed sodium hydroxide pellets $(125.4 \mathrm{mmol}$, $5.016 \mathrm{~g})$ in $99.8 \%$ methanol $(200.0 \mathrm{~mL})$. The sodium hydroxide was dissolved in the methanol through gently swirling the mixture in an Erlenmeyer flask for 180-300 seconds. Soybean oil (549.0 g, $600.0 \mathrm{~mL}$ ) was combined with the freshly prepared sodium methoxide solution in a painted $1000 \mathrm{~mL}$ round bottom flask and heat to reflux $\left(70^{\circ} \mathrm{C}\right)$ for one hour using solar irradiation as the heat source. Biodiesel product (510.3 g, 93.0\%) was collected and dried using anhydrous sodium sulfate (5.023 g). ${ }^{13} \mathrm{C}(\mathrm{ppm})\left(\mathrm{CDCl}_{3}\right): 174.1,130.1,129.9,127.9,51.2,33.9$, $\delta 31.872,29.6,29.4,29.5,29.31,29.1,29.0,29.0,27.1,25.5$, 24.7, 22.6, 22.5, 14.1, 13.9. GC: $16.209 \mathrm{~min}$. MS (m/z): 55.0, 69.0, 73.9 (base peak), 87.0, 101.0, 128.9, 143.0, 171.0, 185.1, 199.1, 227.1, 241.1, $270.0\left(\mathrm{~m}^{+}\right.$peak - palmitic acid methyl ester). GC: $19.138 \mathrm{~min}$. MS (m/z): 55. , 66.9 (base peak), 80.9, 95.0, 109.0, 123.0, 135.0, 149.0, 177.9, 261.9, 294.0 ( $\mathrm{m}^{+}$peak -methyl linoleate). GC: $19.224 \mathrm{~min}$. MS (m/z): 55.0, 66.9 (base peak), 80.9, 95.0, 109.0, 123.0, 135.0, 166.0, 221.0, 264.2, $296.0\left(\mathrm{~m}^{+}\right.$peak -methyl oleate). GC: $19.685 \mathrm{~min}$. MS (m/z): 55.0, 66.9, 73.9 (base peak), 80.9, 87.0, 96.9, 143.0, 199.1, 213.1, 227.1, 241.1, 255.1, 282.8, $298.0\left(\mathrm{~m}^{+}\right.$peak -methyl stearate).

\section{Biodiesel synthesis (medium scale - using ethanol)}

A solution of sodium ethoxide was prepared by dissolving crushed sodium hydroxide pellets $(141.8 \mathrm{mmol}, 5.670 \mathrm{~g}$ ) in 200 proof - absolute, anhydrous ethanol (200.0 mL). The sodium hydroxide was dissolved in the ethanol through gently swirling the mixture in an Erlenmeyer flask for 420-600 seconds. Soybean oil (548.0 g, $600.0 \mathrm{~mL}$ ) was combined with the freshly prepared sodium ethoxide solution in a painted $1000 \mathrm{~mL}$ round bottom flask and heat to reflux $\left(83^{\circ} \mathrm{C}\right)$ for one hour using solar irradiation as the heat source. Biodiesel product (519.3 g, 94.4\%) was collected and dried using anhydrous sodium sulfate $(5.002 \mathrm{~g}) .{ }^{13} \mathrm{C}$ NMR (ppm) $\left(\mathrm{CDCl}_{3}\right): 173.8,129.8,127.9,127.8,60.1,34.2,31.5,29.6$, 29.6, 29.5, 29.2, 29.1, 29.0, 27.1, 25.4, 24.8, 22.4, 14.2, 13.3. GC: $17.334 \mathrm{~min}$. MS (m/z): 55.0, 73.0, 87.9 (base peak), 100.8, 114.9, 128.9, 143.0, 157.0, 171.0, 185.0, 198.8, 213.1, 227.1, 241.1, $284.0\left(\mathrm{~m}^{+}\right.$peak - palmitic acid ethyl ester). GC: $20.205 \mathrm{~min}$. MS (m/z): 55.0, 66.9 (base peak), 80.9, 95.0, 109.0, 120.9, 134.9, 149.0, 164.0, 178.0, 262.1, $308.0\left(\mathrm{~m}^{+}\right.$peak - ethyl linoleate). GC: $20.324 \mathrm{~min}$. MS (m/z): 55.0 (base peak), 66.9, 81.0, 96.0, 123.1, 135.1, 166.0, 180.0, 222.1, 246.0, 264.2, $310.0\left(\mathrm{~m}^{+}\right.$ peak -ethyl oleate). GC: $20.831 \mathrm{~min}$. MS (m/z): 55.0, 61.0, 73.1, 87.8 (base peak), 100.8, 114.8, 128.9, 142.9, 
157.0, 171.2, 185.1, 213.1, 227.1, 241.1, 255.1, 269.1, 283.0, $311.9\left(\mathrm{~m}^{+}\right.$peak - ethyl stearate).

\section{Biodiesel synthesis (large scale - using methanol)}

A solution of sodium methoxide was prepared by dissolving crushed sodium hydroxide pellets $(502.8 \mathrm{mmol}$, $20.111 \mathrm{~g})$ in $99.8 \%$ methanol $(700.0 \mathrm{~mL})$. The sodium hydroxide was dissolved in the methanol through gently swirling the mixture in an Erlenmeyer flask for 300-600 seconds. Soybean oil (1882.9 g, $2400.0 \mathrm{~mL})$ was combined with the freshly prepared sodium methoxide solution in a painted $4000 \mathrm{~mL}$ round bottom flask and heat to reflux $\left(70^{\circ} \mathrm{C}\right)$ for one hour using solar irradiation as the heat source. Biodiesel product (1734.2 g, 92.1\%) was collected and dried using anhydrous sodium sulfate (50.107 g). ${ }^{13} \mathrm{C}$ NMR (ppm) $\left(\mathrm{CDCl}_{3}\right): 173.9,129.8,127.9$, $127.8,60.0, \delta 34.225,31.4,29.6,29.6,29.5,29.2,29.1$, 29.0, 27.1, 25.5, 24.8, 22.5, 14.1, 13.9. GC: $16.201 \mathrm{~min}$. MS (m/z): 55.0, 69.0, 73.9 (base peak), 87.1, 101.0, 128.9, 143.0, 171.0, 185.1, 199.1, 227.1, 241.1, 270.0 (m peak palmitic acid methyl ester). GC: $19.134 \mathrm{~min}$. MS (m/z): 55.0, 66.9 (base peak), 80.9, 95.0, 109.0, 123.0, 135.0, 149.0, 178.0, 262.0, $294.0\left(\mathrm{~m}^{+}\right.$peak -methyl linoleate). GC: $19.218 \mathrm{~min}$. MS (m/z): 55.0, 66.9 (base peak), 80.9, 95.0, 109.0, 123.0. 135.0, 166.0, 221.0, 264.2, $296.0\left(\mathrm{~m}^{+}\right.$ peak -methyl oleate). GC: $19.687 \mathrm{~min}$. MS (m/z): 55.0, 66.9, 73.9 (base peak), 80.9, 87.0, 96.9, 143.0, 199.1, 213.1, 227.1, 241.1, 255.1, 282.8, $298.0\left(\mathrm{~m}^{+}\right.$peak -methyl stearate).

\section{Crude glycerol purification general procedure}

The crude glycerol obtained during the synthesis of biodiesel was purified by first adding concentrated $\mathrm{HCl}$ until the solution reached a $\mathrm{pH}$ of $3-4$. This caused the solution to form two different layers. The top layer was free fatty acids (FFA), which could be reused to generate more biodiesel. The bottom layer was a mixture of glycerol and excess alcohol that was used during the reaction. In order to separate the glycerol from the alcohol, a simple distillation was performed using the solar reflector heat source as the sole heat source for the process. The crude glycerol was placed into a round bottom flask that had been painted black using $\mathrm{VHT}^{\oplus}$ Flame Proof paint and was attached to the simple distillation set-up (Figure 4). The solar heat source was moved into a position in which it was reflecting sunlight onto the bottom of the round bottom flask. The solution was allowed to heat to a temperature of $100^{\circ} \mathrm{C}$ in order to distill off any unreacted alcohol and water from the crude glycerol product. Once distillation ceased, pure glycerol had been isolated and unused alcohol had been recycled for future use.

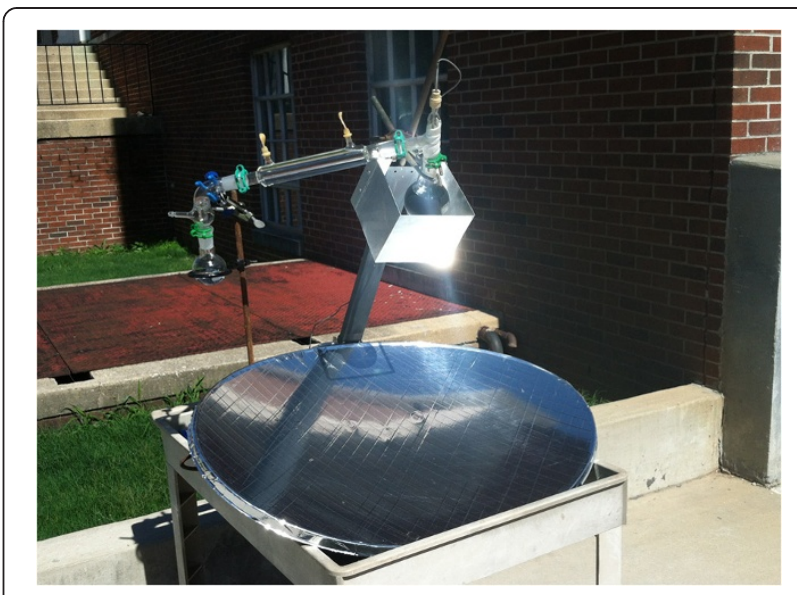

Figure $\mathbf{4}$ Solar distillation set-up. Distillation set-up to purify recovered glycerol.

\section{Purification of recovered glycerol (small scale - using methanol)}

The waste glycerol layer $(15 \mathrm{~mL})$ from the biodiesel synthesis was made acidic ( $\mathrm{pH}=3-4)$ by adding conc. $\mathrm{HCl}$. Once acidic, the glycerol/methanol layer was isolated. The crude, recovered glycerol $(10 \mathrm{~mL})$ was then made slightly basic $(\mathrm{pH}=6-7)$ by adding a small amount of $\mathrm{KOH}$ and mixed with decolorizing charcoal. The resulting solution was then filtered into a painted round bottom flask and attached to a simple distillation set-up using the solar reflector heat source. Methanol $(7 \mathrm{~mL})$ was distilled away from the glycerol solution by heating the solution to $100^{\circ} \mathrm{C}$ using solar irradiation. Recovered, pure glycerol $(3 \mathrm{~mL}, 4.094 \mathrm{~g})$ remained in the round bottom flask. ${ }^{1} \mathrm{H}$ NMR (DMSO-d 6 ): $\delta 4.522$ (s, $\left.1 \mathrm{H}\right), \delta 3.4587-$ 3.325. ${ }^{13} \mathrm{C}$ NMR (DMSO- $\left.\mathrm{d}_{6}\right): \delta 72.58, \delta 63.13$.

\section{Purification of recovered glycerol (small scale - using ethanol)}

The waste glycerol layer $(25 \mathrm{~mL})$ from the biodiesel synthesis was made acidic $(\mathrm{pH}=3-4)$ by adding conc. $\mathrm{HCl}$. Once acidic, the glycerol/ethanol layer was isolated. The crude, recovered glycerol $(15 \mathrm{~mL})$ was then made slightly basic $(\mathrm{pH}=6-7)$ by adding a small amount of $\mathrm{KOH}$ and mixed with decolorizing charcoal. The resulting solution was then filtered into a painted round bottom flask and attached to a simple distillation set-up using the solar reflector heat source. Ethanol $(17 \mathrm{~mL})$ was distilled away from the glycerol solution by heating the solution to $100^{\circ} \mathrm{C}$ using solar irradiation. Recovered, pure glycerol (3 $\mathrm{mL}, 4.127 \mathrm{~g}$ ) remained in the round bottom flask. ${ }^{1} \mathrm{H}$ NMR (ppm) (DMSO- $\mathrm{d}_{6}$ ): 4.512 (s, 1H), 3.4497-3.315. ${ }^{13} \mathrm{C}$ NMR (ppm) (DMSO$\left.\mathrm{d}_{6}\right): 72.3,63.1$. 


\section{Purification of Recovered Glycerol (medium scale - using methanol)}

The waste glycerol layer $(195 \mathrm{~mL})$ from the biodiesel synthesis was made acidic $(\mathrm{pH}=3-4)$ by adding conc. $\mathrm{HCl}$. Once acidic, the glycerol/methanol layer was isolated. The crude, recovered glycerol $(84 \mathrm{~mL})$ was then made slightly basic $(\mathrm{pH}=6-7)$ by adding a small amount of $\mathrm{KOH}$ and mixed with decolorizing charcoal. The resulting solution was then filtered into a painted round bottom flask and attached to a simple distillation set-up using the solar reflector heat source. Methanol $(50 \mathrm{~mL})$ was distilled away from the glycerol solution by heating the solution to $100^{\circ} \mathrm{C}$ using solar irradiation. Recovered, pure glycerol $(34 \mathrm{~mL}, 42.9 \mathrm{~g})$ remained in the round bottom flask. ${ }^{1} \mathrm{H}$ NMR (ppm) (DMSO-d $\left.\mathrm{d}_{6}\right): 4.512$ (s, 1H), 3.4667-3.305. ${ }^{13} \mathrm{C}$ NMR (ppm) (DMSO-d $\left.\mathrm{d}_{6}\right): 72.3$, 63.0.

\section{Purification of recovered glycerol (medium scale - using ethanol)}

The waste glycerol layer $(200 \mathrm{~mL})$ from the biodiesel synthesis was made acidic $(\mathrm{pH}=3-4)$ by adding conc. $\mathrm{HCl}$. Once acidic, the glycerol/ethanol layer was isolated. The crude, recovered glycerol $(86 \mathrm{~mL})$ was then made slightly basic ( $\mathrm{pH}=6-7$ ) by adding a small amount of $\mathrm{KOH}$ and mixed with decolorizing charcoal. The resulting solution was then filtered into a painted round bottom flask and attached to a simple distillation set-up using the solar reflector heat source. Ethanol (57 mL) was distilled away from the glycerol solution by heating the solution to $100^{\circ} \mathrm{C}$ using solar irradiation. Recovered, pure glycerol $(29 \mathrm{~mL}, 36.5 \mathrm{~g})$ remained in the round bottom flask. ${ }^{1} \mathrm{H}$ NMR (ppm) (DMSO- $\left.\mathrm{d}_{6}\right)$ : 4.574 (s, 1H), 3.444-3.301. ${ }^{13} \mathrm{C}$ NMR (ppm) (DMSO-d $\left.\mathrm{d}_{6}\right): 72.7,63.5$.

\section{Purification of recovered glycerol (large scale - using methanol)}

The waste glycerol layer $(700 \mathrm{~mL})$ from the biodiesel synthesis was made acidic $(\mathrm{pH}=3-4)$ by adding conc. $\mathrm{HCl}$. Once acidic, the glycerol/methanol layer was isolated. The crude, recovered glycerol $(300 \mathrm{~mL})$ was then made slightly basic $(\mathrm{pH}=6-7)$ by adding a small amount of $\mathrm{KOH}$ and mixed with decolorizing charcoal. The resulting solution was then filtered into a painted round bottom flask and attached to a simple distillation set-up using the solar reflector heat source. Methanol $(175 \mathrm{~mL})$ was distilled away from the glycerol solution by heating the solution to $100^{\circ} \mathrm{C}$ using solar irradiation. Recovered, pure glycerol (125 mL, $157.6 \mathrm{~g})$ remained in the round bottom flask. ${ }^{1} \mathrm{H}$ NMR (ppm) (DMSO- $\mathrm{d}_{6}$ ): 4.520 (s, $1 \mathrm{H}), 3.459-3.315 .{ }^{13} \mathrm{C}$ NMR (ppm) (DMSO-d $\mathrm{d}_{6}$ ): 72.6, 63.2.

\section{Wolff-Kishner reduction general procedure}

The following conditions are based on a modified version of the Huang-Minlon Wolff-Kishner reduction reaction [18]. A solution of recovered biodiesel glycerol and $\mathrm{KOH}$

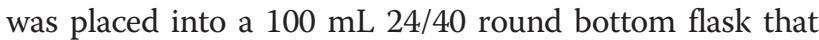
had been painted black using $\mathrm{VHT}^{\ominus}$ Flame Proof paint. No stir-bar is placed into the flask since the refluxing liquid was sufficient to thoroughly mix the solutions. The flask was attached to the solar reflector in the position that the feed horn of the satellite dish was located to provide the best location for the directed focal point of sunlight. A modified Baum et al. Allign-type condenser was filled with propylene glycol and capped with pipet bulbs to insure that the propylene glycol stayed in the condenser [19]. The solar heat source was then moved into a position in which it was reflecting sunlight such that the sunlight was directed at the bottom of the round bottom flask. The solution was allowed to heat until the $\mathrm{KOH}$ dissolved into the solution. Once the $\mathrm{KOH}$ was dissolved the apparatus was moved out of the focal point and the solution was allowed to cool until it reached a temperature of $80^{\circ} \mathrm{C}$. After the solution had cooled, isobutyrophenone and hydrazine hydrate was added to the reaction flask and the solar reflector was moved back into position in which the focal point was directed at the bottom of the round bottom flask. Reflux was initiated for a period of three hours. After acid work-up, glycerol went into the water phase and the reduction product was separated and purified through vacuum distillation.

\section{Wolff-Kishner reduction of isobutyrophenone}

A solution of glycerol (342.3 mmol, $31.523 \mathrm{~g}, 25.0 \mathrm{~mL}$ ) and $\mathrm{KOH}$ (76.4 mmol, $4.285 \mathrm{~g}$ ) was heated to make the basic solvent solution needed for the reaction. After the solution had cooled, isobutyrophenone $(21.7 \mathrm{mmol}$, $3.215 \mathrm{~g}$ ) and hydrazine hydrate $(96.3 \mathrm{mmol}, 3.00 \mathrm{~mL}$, $3.087 \mathrm{~g}$ ) was added and the solar reflector was moved back into position in which the focal point was directed at the bottom of the round bottom flask. Reflux was initiated for a period of three hour at a temperature of $149-155^{\circ} \mathrm{C}$. After acid work-up, pure isobutyl benzene (15.0 mmol, $2.019 \mathrm{~g}, 70.0 \%$ ) was collected through vacuum distillation at $4 \mathrm{inHg}$ at a temperature range of 105$110^{\circ} \mathrm{C} .{ }^{1} \mathrm{H}$ NMR (ppm) $\left(\mathrm{CDCl}_{3}\right): 7.33-7.19,2.53(\mathrm{~d}, \mathrm{~J}=$ $6.9 \mathrm{~Hz}, 2 \mathrm{H}), 1.87(\mathrm{n}, \mathrm{J}=6.8 \mathrm{~Hz}, 1 \mathrm{H}), 0.96(\mathrm{~d}, \mathrm{~J}=6.6 \mathrm{~Hz}$, $6 \mathrm{H}) .{ }^{13} \mathrm{C}$ NMR (ppm) $\left(\mathrm{CDCl}_{3}\right): 141.7,129.1,128.1,125.6$, 45.5, 30.2, 22.4. GC: $5.14 \mathrm{~min}$. MS (m/z): 50.1, 65.0, 77.0, 91.0 (base peak), 103.1, 115.3, 134.0 ( $\mathrm{m}^{+}$peak).

\section{Conclusion}

This work has demonstrated that the solar heat source that was modified from the previous publication can be used successfully in the place of an electric heating source. Using the current set-up which employs the use of an HD 
satellite dish $(81 \mathrm{~cm} \times 55 \mathrm{~cm})$ and the much larger dish $(89 \mathrm{~cm} \times 99 \mathrm{~cm})$, a technique was successfully developed to use solar energy to provide enough thermal heat to perform transesterification reactions to produce biodiesel on the millimolar and molar scale. Furthermore, it appears that outside ambient temperature does not affect whether or not the dish is capable of being used in a chemical reaction. As long as there is enough sunlight to produce at least $400-450 \mathrm{~W} / \mathrm{m}^{2}$ of solar irradiation, this set-up will provide enough energy to perform most chemical operations.

In this study, biodiesel was successfully synthesized in a cradle to grave manner in which there was no waste generated (both through chemical use and electricity use). During the synthetic process, no waste was generated as any unreacted alcohol was recovered, recovered FFA was used to generate more biodiesel, and waste glycerol was recovered and purified to use in other processes. Furthermore, no electrical waste was generated because all thermal energy was supplied through sunlight. As a side benefit, a method of incorporating the waste glycerol from the synthesis of biodiesel into another synthetic process was developed.

It is believed that modifications that have been made to the solar reflector heat source since the last publication have aided in the sustainability of the reflector as a valid replacement for electric heat sources. By enhancing the size of the dish, the potential power of the dish from the previous publication has been significantly increased. As a direct effect, nearly 2.5 liters of biodiesel was synthesized in slightly less than one hour of heating. By using the solar reflector heat source, no electrical waste is being generated since the only energy being used is the energy from the sun, which is a renewable source.

In the future, plans are being developed to continue attempting to extend the efficiency of this reflector as a heat source. One area that is still uncertain, especially concerning the newly devised $81 \mathrm{~cm} \times 55 \mathrm{~cm}$ solar reflector, is what size of a reaction could be performed using this set-up. Using the much larger $89 \mathrm{~cm} \times 99 \mathrm{~cm}$ dish, investigations involving the scalability of the set-up in order to see if it could be incorporated into certain aspects of industrial reactions could be conducted. Currently investigations involving various techniques that could be employed during the purification step of the Wolff-Kishner reduction reaction are being studied. This is the only process in this publication that was required to use electricity (vacuum distillation). Attempts are being made to remove the consumption of energy during this step. Other well know chemical reactions are also being investigated using the solar reflector as the sole heat source, as well as multi-step synthetic reactions that are used to synthesize commercial products of great importance to the general public. The results of using our solar reflector in other organic synthesis reactions, and its further development will be released in future publications [22].

\section{Methods}

\section{Development of the solar heat source}

The same design for the solar reflector was used as the reflector in our previous publication [17]. However, the heating block heat sink was removed. To use the reflector without the aluminum heating block as a heat sink, round bottom flasks were painted black up to approximately half-way up the flask using $\mathrm{VHT}^{\circ}$ Flame Proof paint, which can withstand intermittent temperatures up to $1093^{\circ} \mathrm{C}$ (Figures 1 and 2). The round bottom flasks were painted to prevent photochemical side reactions and allow for a more efficient heating process.

To perform the reactions in this study, two different solar reflectors were incorporated into the reaction procedure. For the first two scaled reactions (millimolar), a solar reflector was used that was developed out of an $81 \mathrm{~cm} \times 55 \mathrm{~cm}$ satellite dish (Figure 1). For the reaction that incorporated a molar scale reaction, a $89 \mathrm{~cm} \times$ $99 \mathrm{~cm}$ satellite dish, commonly referred to as the D.E.A. T.H. (Directed Energy Amplified Thermal Heating) dish, was used (Figure 3). The reason for the change in solar reflectors was to provide a larger surface area, which in turn would provide more energy to thoroughly heat the much larger mole scale reaction.

\section{Experimental methods}

NMR spectra were obtained using a Varian Mercury VX-300 Multi-Nuclear FT-NMR Spectrometer operating at $300 \mathrm{MHz}$. Chemical shifts for each peak in the spectra were measured in parts per million (ppm) relative to tetramethylsilane (TMS). Biodiesel and Wolff-Kishner products were analyzed in deuterated chloroform $\left(\mathrm{CDCl}_{3}\right)$, while purified glycerol was analyzed in deuterated dimethyl sulfoxide (DMSO- $\mathrm{d}_{6}$ ). As verification, the spectral database for organic compounds states that glycerol should have a ${ }^{1} \mathrm{H}$ NMR spectrum with ppm chemical shifts of 4.48, 3.448, 3.382, and 3.310 and a ${ }^{13} \mathrm{C}$ NMR spectrum with ppm chemical shifts of 72.37 and 63.05 [23].

A Varian CP-3800 Gas Chromatograph was used with a Varian Saturn 2200 GC/MS/MS detector and a Varian VF-5MS 30MX0.25 mm ID DF $=0.25$ column (Catalog No. CP8944) and CombiPAL auto sampler were used to obtain the GC/MS spectra. A 1:1000 dilution of sample in 2-propanol was found to be the best concentration of the samples. Also, in order to avoid the appearance of nitrogen, oxygen, and water vapor in the spectra, the mass detector was set to detect only ions with a mass over $40 \mathrm{~m} / \mathrm{z}$.

The type of oil that was incorporated into the biodiesel synthesis procedure for this project was soybean oil. Soybean oil consists of Linoleic Acid (54\%, poly unsaturated), 
Table 7 Soybean esters molecular weights

\begin{tabular}{lll}
\hline Acid & Ester & Molecular weight $\mathbf{( g / m o l})$ \\
\hline Linoleic & Methyl linoleate & 294 \\
Linoleic & Ethyl linoleate & 308 \\
a-Linoleic & a-Linoleic acid methyl ester & 294 \\
a-Linoleic & a-Linoleic acid ethyl ester & 308 \\
Oleic & Methyl oleate & 296 \\
Oleic & Ethyl oleate & 310 \\
Palmitic & Palmitic acid methyl ester & 270 \\
Palmitic & Palmitic acid ethyl ester & 284 \\
Steric & Methyl stearate & 298 \\
Steric & Ethyl stearate & 312 \\
\hline
\end{tabular}

$\alpha$-Linoleic Acid (7\%, poly unsaturated), Oleic Acid (24\%, mono unsaturated), Palmitic Acid (11\%, saturated), and Steric Acid (4\%, saturated). After undergoing the transesterification reaction to produce biodiesel, these acids will be present as either methyl- or ethyl- esters. The molecular weight of these esters can be used as an identification tool through the use of GC/MS (Table 7).

\section{Competing interests}

The authors declare that they have no competing interests.

\section{Authors' contributions}

BA carried out the synthesis, purification, and NMR characterization of the compounds, and aided in drafting the manuscript. GM carried out the GC/MS characterization of the compounds. DS conceived of the study, and participated in its design, aided in the synthesis of the compounds, and helped to draft the manuscript. All authors read and approved the final manuscript.

\section{Acknowledgements}

Funding for this research was provided by Tennessee Technological University.

\section{Author details}

'Department of Environmental Sciences, Tennessee Technological University, Cookeville, TN 38505, USA. ${ }^{2}$ Department of Chemistry, Tennessee

Technological University, Cookeville, TN 38505, USA.

Received: 7 July 2014 Accepted: 23 September 2014

Published online: 07 October 2014

\section{References}

1. Cowen R: History of Life. Oxford: Blackwell Science; 2000.

2. Stocker T, Quin D, Platner G-K: Climate Change 2013 The Physical Science Basis. Cambridge: Cambridge University Press; 2013.

3. Nigam PS, Singh A: Production of liquid biofuels from renewable resources. Prog Energy Combustion Sci 2011, 37:52-68.

4. Knothe G, Karhl J, Van Gerpen J (Eds): The Biodiesel Hand Book. Champaign: AOCS Press; 2005.

5. Biodiesel: Renewable Domestic Fuel Available Today. [http://www.brevardbiodiesel.com]

6. Tickell J: From the Fryer to the Fuel Take: The Complete Guide to Using Vegetable Oil as an Alternative Fuel. Ashland: BookMasters; 2003.

7. Nye MJ, Williamson TW, Deshpade S, Schrader JH, Snively WH: Conversion of used frying Oil to diesel fuel by transesterification: preliminary tests. J Am Oil Chem Soc 1983, 60:1598-1601.

8. Biodiesel Synthesis. Green Chemistry Workshop. 2007 [https://www.istemnetwork.org/resource/learning]
9. Pryor SC, Barthelmie RJ: Assessing climate change impacts on the near-term stability of the wind energy resource over the United States. Proc Natl Acad Sci U S A 2011, 108:8167-8171.

10. World Energy Outlook. [http://www.worldenergyoutlook.org/resources/ energydevelopment/energyaccessdatabase/]

11. Vale A: Methanol. Medicine 2007, 35:633-634

12. Mills GA, Ecklund EE: Alcohols as components of transportation fuels. Annu Rev Energy 1987, 12:47-80.

13. Yost D: Postgraduate medicine online. 112(6): [https://web.archive.org/ web/20101214113109/http://my.lecom.edu/library/internetresources/journal \%20articles/Acute\%20Care\%20for\%20Alcohol\%20Intoxication.pdf]

14. Evolving Technology May Generate Profit From Biodiesel Glycerin Glut. [http://www.rurdev.usda.gov/rbs/pub/jul07/Evolving.htm. Accessed: December 17, 2013]

15. Kiss $A A$, Ignat RM: Enhanced methanol recovery and glycerol separation in biodiesel production - DWC makes It happen. Appl Energy 2012, 99:146-153.

16. Amereco Biofuels. [http://www.amerecobiofuels.com/Home.html]

17. Agee B, Mullins $G$, Swartling D: Friedel-crafts acylation using solar irradiation. ACS Sustainable Chem Eng 2013, 1:1580-1583.

18. Kill A Watt. [http://www.p3international.com/products/p4400.html]

19. Greenhouse Gas Equivalencies Calculator. [http://www.epa.gov/ cleanenergy/energy-resources/calculator.html]

20. Agee B, Mullins G, Biernacki J, Swartling D: Wolff-Kishner reduction reactions using a solar irradiation heat source and a green solvent system. Green Chem Lett Rev 2014, Accepted for Publication Sept. 2014 doi:10.1080/17518253.2014.966866.

21. Baum E, O'Callaghan I, Cinninger L, Esteb J, Wilson A: Static fluid condensers for the containment of refluxing solvent. ACS Sustain Chem Eng 2013, 1:1502-1505.

22. Agee B, Swartling D: Development of a Solar Reflector for Use in Organic Synthesis Reactions. In Proceedings of the $17^{\text {th }}$ ACS Green Chemistry \& Engineering Conference. Bethesda, MD, United States; 2013. GCE-111. Database: CAPLUS.

23. Spectral Database for Organic Compounds. [http://sdbs.db.aist.go.jp/sdbs/ cgi-bin/direct_frame_top.cgi]

doi:10.1186/s40508-014-0021-2

Cite this article as: Agee et al:: Use of solar energy for biodiesel production and use of biodiesel waste as a green reaction solvent. Sustainable Chemical Processes 2014 2:21.

\section{Publish with ChemistryCentral and every scientist can read your work free of charge \\ "Open access provides opportunities to our colleagues in other parts of the globe, by allowing anyone to view the content free of charge." W. Jeffery Hurst, The Hershey Company. \\ - available free of charge to the entire scientific community \\ - peer reviewed and published immediately upon acceptance \\ - cited in PubMed and archived on PubMed Central \\ - yours - you keep the copyright \\ Submit your manuscript here: \\ http://www.chemistrycentral.com/manuscript/ \\ () \\ Chemistry Central}

